\title{
Structural and optical changes of undoped GaN layers grown via radio-frequency magnetron sputtering obtained from $\mathrm{GaN}$ powders
}

\author{
E. Gastellóu, C. Morales, G. García, R. García, G. A. Hirata, A. M. Herrera, R. Galeazzi, E. Rosendo, \\ T. Díaz, R. Romano and A. Coyopol
}

\begin{abstract}
Undoped GaN layers were grown via radiofrequency magnetron sputtering, using a target manufactured with undoped GaN powders. Where the GaN powders were sintetized by nitridation of metallic gallium at $1000{ }^{\circ} \mathrm{C}$ in ammonia flow for two hours. X-ray diffraction patterns demonstrated that there are not a significant difference between the diffraction angles of the GaN powders and the GaN layers. The $x$-ray diffraction patterns for the GaN powders showed narrow peaks with a crystal size of $41 \mathrm{~nm}$, while the GaN layers showed broad peaks with a crystal size of 7.7 nm. Scanning electron microscopy micrographs demonstrated the formation of crystals of irregular size with an average length of $1.56 \mu \mathrm{m}$ for the GaN powders, while a homogeneous surface morphology with a thickness of $6.6 \mu \mathrm{m}$ for the GaN layers was observed. Photoluminescence spectra showed a high emission at $3.49 \mathrm{eV}(355.13 \mathrm{~nm})$ for the GaN powders and an emission band energy located at $3.42 \mathrm{eV}$ $(361.54 \mathrm{~nm})$ for the GaN layers, both emission bands were related to the band-to-band transition for the GaN. Raman spectra for the GaN powders showed the $A_{1}(T O), E_{1}(T O)$, and $\mathrm{E}_{2}$ (High) classical vibration modes. The GaN layers only showed the $A_{1}(T O)$ mode.
\end{abstract}

Index Terms - GaN; Layers; Powders; Sputtering.

\section{INTRODUCTION}

The III-V semiconductor compounds have attracted the interest of the researchers due to its direct band gap, inside of the III-V semiconductor compounds, the group III Nitride ( GaN, AlN and InN) stands out because of their optical and electrical properties. Gallium nitride $(\mathrm{GaN})$ was at first synthesized in 1932 by Johnson - Parson - Crew [1] and its importance was demonstrated by Radio Corporation of America laboratories (RCA) in 1968 [2]. Nowadays the $\mathrm{GaN}$ is a fundamental material for the LED lighting technology, with applications in the conservation of electrical energy and the reduction of emissions to the

Published on February 27, 2019

E. Gastellóu, C. Morales, G. García, A. M. Herrera, R. Galeazzi, E. Rosendo, T. Díaz, R. Romano and A. Coyopol are with the Centro de Investigación en Dispositivos Semiconductores, Benemérita Universidad Autónoma de Puebla (BUAP), Puebla, Puebla, C.P. 72570, México (e-mail: erick_gastellou@utpuebla.edu.mx, crisomr@yahoo.com.mx, godgarcia@yahoo.com, anhe_26@hotmail.com, ingquim25@gmail.com, enrique171204@gmail.com,

roman.romano@gmail.com, acoyopol@gmail.com).

R. García is with the Departamento de Investigación en Física, Universidad de Sonora (USON), Hermosillo, Sonora, C.P. 83190, México (e-mail: rgarcia@cifus.uson.mx).

G. A. Hirata is with the Centro de Nanociencias y Nanotecnología, Universidad Nacional Autónoma de México (UNAM), Ensenada, Baja California Norte, C.P. 22800, México (e-mail: hirata@cnyn.unam.mx). atmosphere produced by hydrocarbons, through the replacement of incandescent bulbs with LED bulbs. Other applications of the GaN are in laser diodes, UV detectors, microwave devices and ultra high power devices [3-6].

The GaN can crystallize in the hexagonal structure (wurtzite, $\mathrm{Eg}=3.4 \mathrm{eV}$ ) or stable phase, and in cubic structure (zinc blende, $\mathrm{Eg}=3.2 \mathrm{eV}$ ) or metastable phase. The structural, optical and electrical properties of the $\mathrm{GaN}$ depend on the growth conditions, as well as on its nucleation process [7 - 9]. GaN layers are generally obtained via metalorganic chemical vapor deposition (MOCVD), metalorganic vapor phase epitaxy (MOVPE), and molecular beam epitaxy (MBE) [10, 11]. However, these methods use substrates with a lattice constant approximate to the GaN, which could produce lattice defects between the substrate and the layer [12]. A form of decrease the difference between substrate and the layer in heteroepitaxy is the buffer layer. The buffer layer generally reduces the difference in the thermal expansion coefficients of the substrate and $\mathrm{GaN}$. A rarely used technique to obtain $\mathrm{GaN}$ buffer layers is radio-frequency magnetron sputtering, which might require the availability of undoped $\mathrm{GaN}$ powders with high purity and single phase to be used as raw material in the targets production [13 - 16]. This work presents the obtaining of undoped $\mathrm{GaN}$ layers via radiofrequency magnetron sputtering, which were grown using a target manufactured with undoped $\mathrm{GaN}$ powders.

\section{EXPERIMENTAL}

Undoped GaN layers were obtained via radio-frequency magnetron sputtering, which were grown using a target manufactured with undoped $\mathrm{GaN}$ powders. The undoped GaN powders were sintetized by nitridation of metallic gallium at $1000{ }^{\circ} \mathrm{C}$ in ammonia flow for two hours. The following describes the processes for obtaining undoped $\mathrm{GaN}$ powders, as well as the undoped GaN layers:

\section{A. Undoped GaN powders}

Undoped $\mathrm{GaN}$ powders were obtained at atmospheric pressure $(744 \mathrm{mmHg})$, using ultra-high purity metallic gallium (99.999\%) as reagents, as well as anhydrous ammonia of ultra-high purity $\left(\mathrm{NH}_{3}\right)$ as reactant gas. To synthesize the undoped $\mathrm{GaN}$ powders, only $3.02 \mathrm{~g}$ (43 mmol) of metallic gallium was used. Equation (1) shows the proposed chemical reaction to synthesize undoped $\mathrm{GaN}$ [17]: 


$$
2 \mathrm{Ga}(\mathrm{l})+2 \mathrm{NH}_{3}(\mathrm{~g}) \rightarrow 2 \mathrm{GaN}(\mathrm{s})+3 \mathrm{H}_{2}(\mathrm{~g})
$$

Metallic gallium was placed in a high-alumina boat and preheated on a hot plate at $200{ }^{\circ} \mathrm{C}$ with manual agitation for two hours. After this time, the metallic gallium was introduced into a three-zone furnace, which was purged three times using $\mathrm{N}_{2}$ flow for 30 minutes at room temperature. The temperature was then increased to $800{ }^{\circ} \mathrm{C}$ and the $\mathrm{N}_{2}$ flow was kept constant at $150 \mathrm{sccm}$ for one hour to remove the oxide from the metallic gallium. Later, the process temperature was raised to $1000{ }^{\circ} \mathrm{C}$ for two hours. When the temperature reached $850{ }^{\circ} \mathrm{C}$, the $\mathrm{NH}_{3}$ flow was opened $(150 \mathrm{sccm})$ and the $\mathrm{N}_{2}$ flow was closed. After the nitridation process was finished, the temperature was lowered to $600{ }^{\circ} \mathrm{C}$, whereupon the NH3 flow was closed and the $\mathrm{N}_{2}$ flow was opened $(150 \mathrm{sccm})$. The temperature was lowered to room temperature. Undoped $\mathrm{GaN}$ synthesized was extracted from the reactor and ground to obtain the GaN powder. The total weight obtained of undoped GaN powders using this process was $3.42 \mathrm{~g}(71.6 \mathrm{mmol})$. A diagram of the process is shown in Fig. 1.

\section{B. Undoped GaN layers}

Once the undoped GaN powders were synthesized, the compression process was performed to obtain the targets for the radio-frequency magnetron sputtering deposit. First, the finest grinding of undoped GaN powders was done, using a mortar in order to homogenize the powders size before its compaction. Then, the undoped $\mathrm{GaN}$ powders were lubricated using $0.5 \mathrm{ml}$ of methanol. Later, they were placed in a crusher and in a blackhawk SP25B press (25 ton). Once the powders were compacted, the target of undoped $\mathrm{GaN}$ powders was extracted. After, the undoped GaN target was individually sintered at $900{ }^{\circ} \mathrm{C}$ for one hour in an $\mathrm{N}_{2}$ flow, into a three-zone furnace. When the target was manufactured, it was introduced in the equipment Kurt J. Lerker of Intercovamex, for the growth of undoped GaN layers on silicon substrates (100), via radio-frequency magnetron sputtering. The equipment has a target size of $25.4 \mathrm{~mm}$ diameter and $5 \mathrm{~mm}$ thickness. The growth conditions of the GaN layers are the following; power of 50 $\mathrm{W}$, empty pressure of 25 mTorr, growth time of 8 hours, distance between substrate and target of $40 \mathrm{~mm}$. All the process was done at room temperature and in nitrogen gas [16]. Fig. 2, shows the undoped GaN target performed with the undoped GaN powders for the obtaining of the undoped GaN layers.

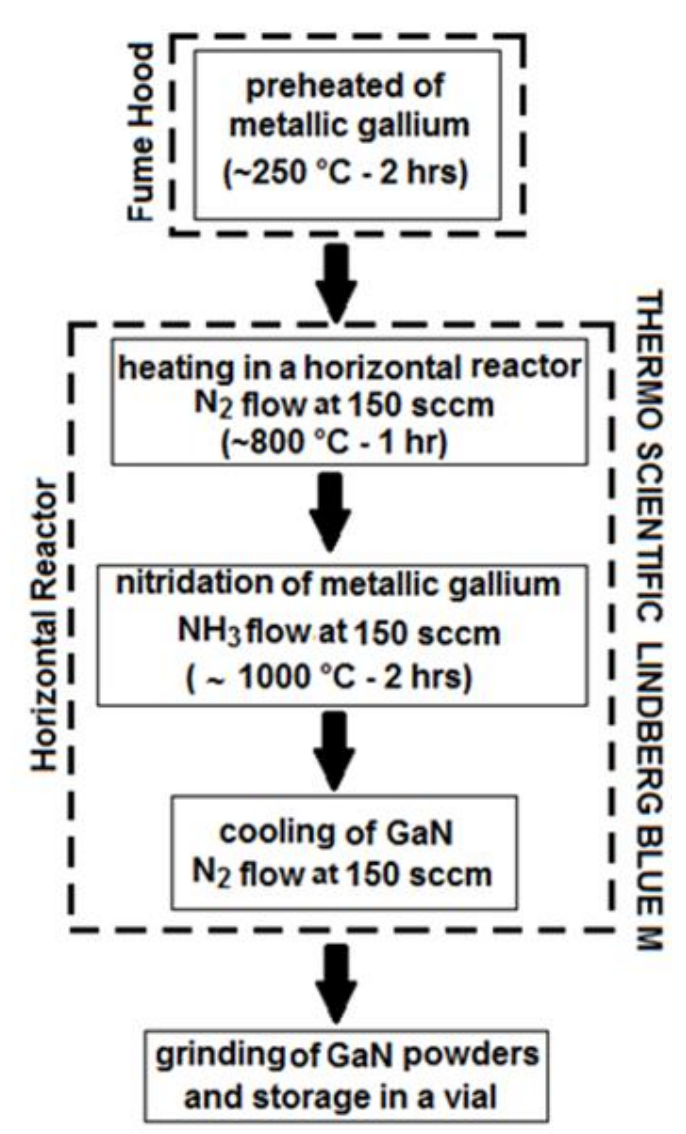

Fig. 1. Process diagram to obtain the undoped GaN powders.

\section{Characterizations}

The undoped GaN layers and undoped GaN powders were characterized by x-ray diffraction (XRD) using a Philips X'PERT MPD equipment with a wavelength $(\mathrm{Cu}$ $\mathrm{K} \alpha$ ) of $1.5406 \AA$. The surface morphology was obtained via scanning electron microscopy (SEM) using a JEOL JSM5300 equipment. Photoluminescence spectra (PL) was measured at room temperature with an excitation wavelength of $243 \mathrm{~nm}$ and a $310 \mathrm{~nm}$ filter using a fluorescence spectrophotometer Hitachi F- 7000 FL with a $150 \mathrm{~W}$ xenon lamp. The Raman scattering characterizations of the undoped $\mathrm{GaN}$ layers and undoped $\mathrm{GaN}$ powders were obtained using a Horiba Jobin Yvon HR-800 Micro Raman spectrophotometer.

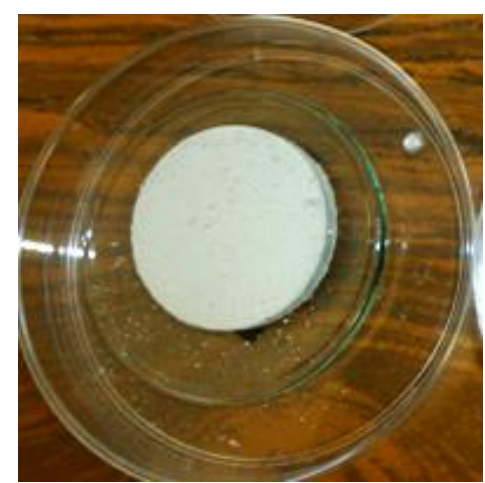

Fig. 2. Undoped GaN target performed with undoped GaN powders obtained by nitridation of metallic gallium. 


\section{RESULTS AND DISCUSSION}

\section{A. Structure}

Fig. 3a) shows the x-ray diffraction pattern of the undoped $\mathrm{GaN}$ powders and the Fig. 3b) presents the x-ray diffraction pattern of the undoped $\mathrm{GaN}$ layers.

The peaks observed in Fig. 3 were indexed in the ICCD card 00-050-0792 for the undoped GaN powders and in the ICCD card 04-003-5899 for the undoped GaN layers. In both cases, the $a$ peak is located in the plane orientation (100), $b$ at (002), $c$, which has the highest intensity, at (101), $d$ at (102), and $e$ at (110). The calculated lattice constants for the wurtzite structure were $\mathrm{a}=3.18 \AA$ and $\mathrm{c}=5.18 \AA$, with ratio c/a of 1.62. It is possible to observe from Fig. 3 that there is not a significant difference between the angles of the diffraction patterns of Fig. 3a) and Fig. 3b). However, the x-ray diffraction pattern in Fig. 3a) showed narrow peaks, which could indicate the presence of large crystals. For undoped GaN powders, the FWHM obtained for (100) plane orientation was $0.15^{\circ}, 0.17^{\circ}$ for $(002), 0.17^{\circ}$ for $(101)$, $0.22^{\circ}$ for (102) and $0.24^{\circ}$ for (110). On the other hand, the x-ray diffraction pattern of Fig. 3b), showed broad peaks, which could indicate the presence of nanocrystals [17]. For undoped GaN layers, the FWHM obtained for (100) plane orientation was $0.86^{\circ}, 1.43^{\circ}$ for $(002), 1.15^{\circ}$ for $(101), 0.01^{\circ}$ for (102) and $1.05^{\circ}$ for (110). Using the ICCD PDF-4+ 2018 software and the Debye-Scherrer equation [18], the crystal size was computed finding an average of $41 \mathrm{~nm}$ for the undoped $\mathrm{GaN}$ powders and an average of $7.7 \mathrm{~nm}$ for the undoped GaN layers.

\section{B. Electron microscopy}

Fig. 4a) shows the surface morphology of the undoped $\mathrm{GaN}$ powders obtained via nitridation of metallic gallium at $1000{ }^{\circ} \mathrm{C}$ for two hours in ammonia flow. In this figure, it is possible to observe crystals of irregular size with an average length of $1.56 \mu \mathrm{m}$. Crystals of different size can be identified at $2200 x$ magnification. Fig. 4b) shows the surface morphology of undoped $\mathrm{GaN}$ layers obtained by radio-frequency magnetron sputtering using an undoped $\mathrm{GaN}$ powders target. Undoped $\mathrm{GaN}$ layers had a thickness of $6.6 \mu \mathrm{m}$, which was measurement using a profilometer. In Fig. 4b) was observed a homogeneous surface morphology. Fig. 4b) also showed some agglomerates of the deposited material. These results agree with the x-ray diffraction patterns showed in Fig. 3.

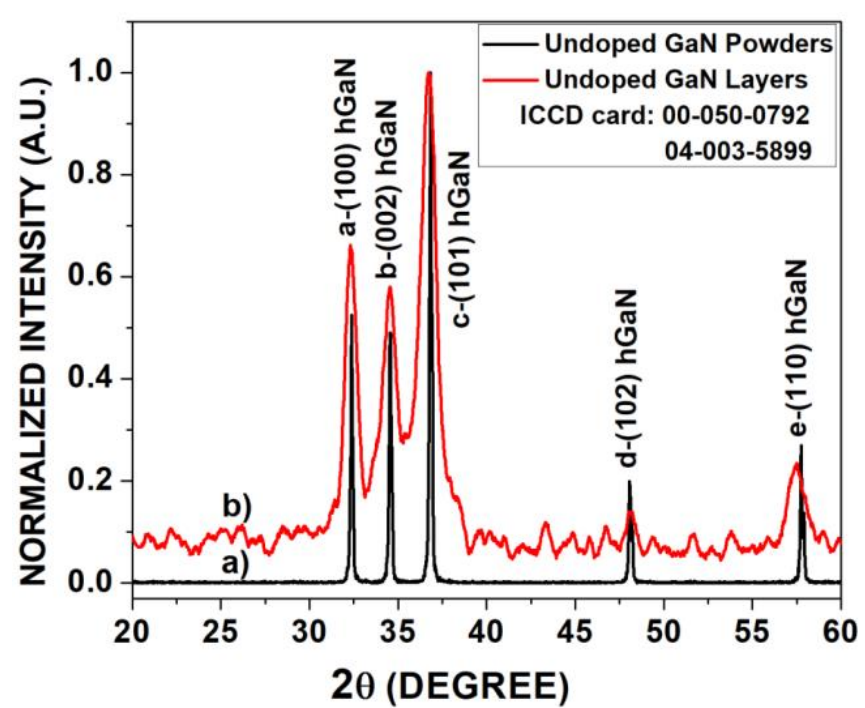

Fig. 3. a) X-Ray diffraction pattern of the undoped GaN powders, b) X-Ray diffraction pattern of the undoped $\mathrm{GaN}$ layers.
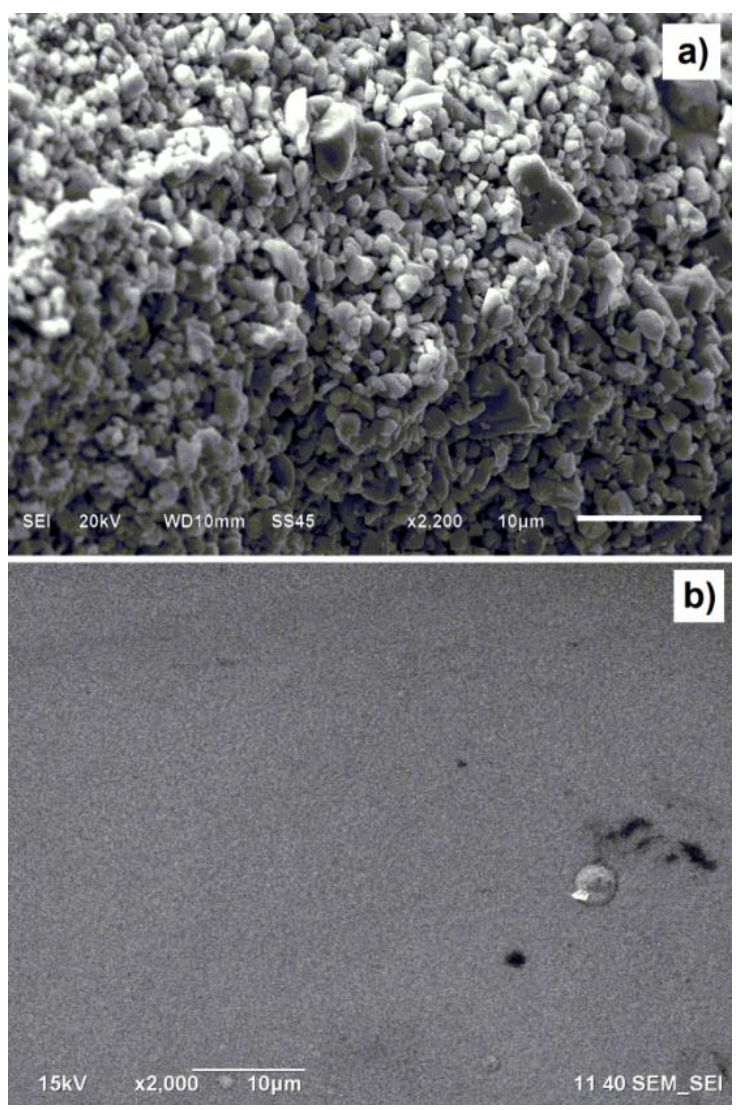

Fig. 4. a) SEM micrograph of the undoped GaN powders, b) SEM micrograph of the undoped GaN layers.

\section{Photoluminescence}

Fig.5 shows the photoluminescence spectra for the undoped GaN powders (black line) and undoped GaN layers (red line), measured at room temperature. The PL spectrum of the undoped $\mathrm{GaN}$ layers was decomposed in four components. The $a$ peak showed a high emission due to the band-to-band transition in $3.49 \mathrm{eV}(355.13 \mathrm{~nm})$, which corresponds to the ultra violet emission for the hexagonal GaN. The emission band energy located at $3.42 \mathrm{eV}(361.54$ $\mathrm{nm})$ ( $b$ peak-first component) corresponds to band-to-band transition also for the hexagonal $\mathrm{GaN}$, where the difference of $0.07 \mathrm{eV}$ between band-to-band emissions could be related 
to the greater amount of structural defects (stacking faults) in the GaN powders [19]. The blue emission band located at $2.96 \mathrm{eV}(418.67 \mathrm{~nm})$ ( $c$ peak-second component) exhibited a metastable blue luminescence, and a yellow luminescence band. The yellow emission band was located at $2.72 \mathrm{eV}$ $(454.83 \mathrm{~nm})$ ( $d$ peak-third component) for the undoped $\mathrm{GaN}$ layers, this is related to transitions from three distinct deep donors to the shallow gallium vacancies acceptor [19]. The e peak (fourth component), showed an emission band energy located at $2.31 \mathrm{eV}(492.73 \mathrm{~nm})$, which is attributed to the complex nature of the yellow luminescence band. Finally, the f peak located in $2.21 \mathrm{eV}(560.37 \mathrm{~nm})$ (redyellow band), is related to the presence of carbon impurities and interstitial gallium atoms [17].

\section{Raman scattering}

Fig. 6 shows the Raman spectra for the undoped GaN powders (black line) and undoped GaN layers (red line) respectively.

The Raman spectrum for the undoped $\mathrm{GaN}$ powders shows the vibration modes $\mathrm{A}_{1}(\mathrm{TO}), \mathrm{E}_{1}(\mathrm{TO})$ and $\mathrm{E}_{2}$ (High) for the wurtzite structure of $\mathrm{GaN}$. From this same figure it was possible to observe the separation between the $\mathrm{E}_{1}(\mathrm{TO})$ and $\mathrm{E}_{2}$ (High) modes, which could confirm the obtaining of Ga-rich $\mathrm{GaN}$ powders [17]. In other hand, the $\mathrm{A}_{1}(\mathrm{TO})$, $\mathrm{E}_{1}(\mathrm{TO})$ and $\mathrm{E}_{2}$ (High) vibration modes were drastically diminished by the Si substrate signal, where it was only possible to observe the $\mathrm{A}_{1}(\mathrm{TO})$ mode, this vibration mode was magnified and showed in the inner inset of Fig. 6 [20, 21]. The frequency values were $525.61 \mathrm{~cm}^{-1}$ for the $A_{1}$ (TO) mode, $546.54 \mathrm{~cm}^{-1}$ for the $\mathrm{E}_{1}(\mathrm{TO})$ mode and $555.58 \mathrm{~cm}^{-1}$ for the $\mathrm{E}_{2}$ (High) vibration mode.

\section{CONCLUSIONS}

Undoped GaN layers were obtained via radio-frequency magnetron sputtering, which were grown using a target manufactured with undoped $\mathrm{GaN}$ powders. The undoped $\mathrm{GaN}$ powders were sintetized by nitridation of metallic gallium at $1000{ }^{\circ} \mathrm{C}$ in ammonia flow for two hours. XRD characterizations showed that there are no a significant difference between the angles of the diffraction patterns. Besides, the x-ray diffraction pattern for the undoped GaN powders showed narrow peaks, which could indicate the presence of large crystals with a crystal size of $41 \mathrm{~nm}$, while for the undoped $\mathrm{GaN}$ layers, the diffraction pattern showed broad peaks, which could indicate the presence of nanocrystals with a crystal size of $7.7 \mathrm{~nm}$. From SEM micrographs it was possible to observe crystals of irregular size with an average length of $1.56 \mu \mathrm{m}$ for the undoped $\mathrm{GaN}$ powders, as well as a homogeneous surface morphology for the undoped $\mathrm{GaN}$ layers with a thickness of $6.6 \mu \mathrm{m}$. PL spectra showed a high emission at $3.49 \mathrm{eV}(355.13 \mathrm{~nm})$ for the undoped $\mathrm{GaN}$ powders, while for the undoped $\mathrm{GaN}$ layers an emission band energy located at $3.42 \mathrm{eV}$ (361.54 $\mathrm{nm}$ ) was observed. These emission bands were related to the band-to-band transition for the hexagonal GaN. The difference of $0.07 \mathrm{eV}$ between band-to-band emissions could be related to the greater amount of stacking faults in the $\mathrm{GaN}$ powders. Raman spectra for the undoped $\mathrm{GaN}$ powders showed the classical vibration modes with values of $525.61 \mathrm{~cm}^{-1}$ for the $\mathrm{A}_{1}$ (TO) mode, $546.54 \mathrm{~cm}^{-1}$ for the $\mathrm{E}_{1}$ (TO) mode and $555.58 \mathrm{~cm}^{-1}$ for the $\mathrm{E}_{2}$ (High) vibration mode. On the other hand, it was only possible to observe the $\mathrm{A}_{1}(\mathrm{TO})$ mode for the undoped GaN layers.

\section{ACKNOWLEDGMENT}

The authors gratefully acknowledge the technical support of CNyN-UNAM, particularly Eloísa Aparicio, Israel Gradilla and Laura Briones. This research was partially supported by CONACyT (México), CIDS-ICUAP-BUAP and VIEP. The first author acknowledges CONACyT for scholarship 405931 and to Information and the Communication Technologies Division of the UTPuebla.

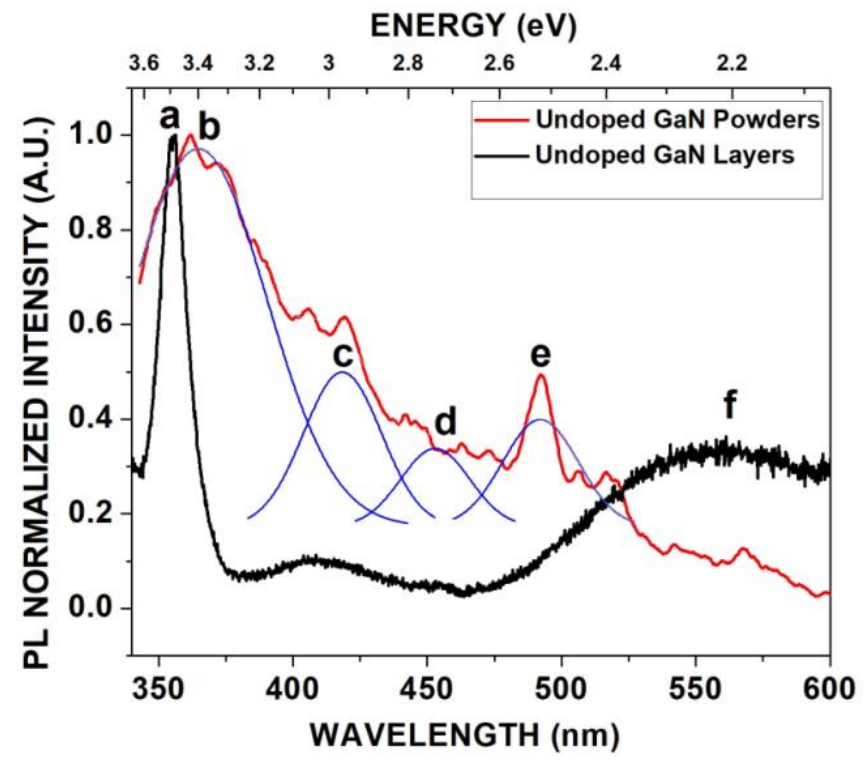

Fig. 5. Photoluminescence spectra for the undoped GaN powders, and undoped GaN layers.

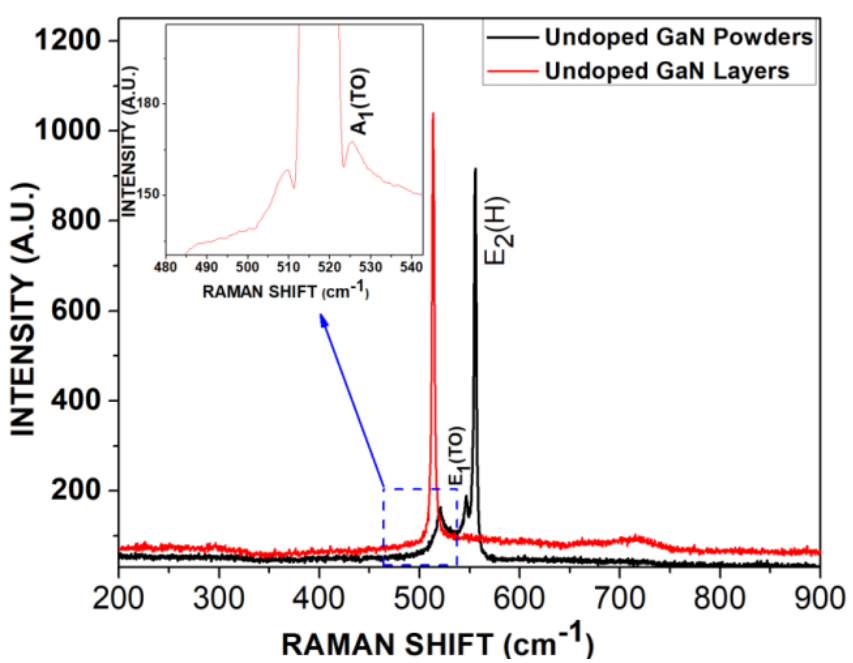

Fig. 6. Raman scattering for the undoped GaN powders, and Raman scattering for the undoped GaN layers. 


\section{REFERENCES}

[1] W.C. Johnson, J.B. Parson, M.C. Crew, Nitrogen compounds of gallium III. J. Phys. Chem. 10(1932) 2651 - 2654. DOI: $10.1021 / \mathrm{j} 150340 \mathrm{a} 01$

[2] H.P. Maruska, W.C. Rhines, A modern perspective on the history of semiconductor nitride blue light sources, Solid States Electronics 111(2015) 32 - 41. https://doi.org/10.1016/j.sse.2015.04.010

[3] S.T. Pearton, J.C. Zolper, R.J. Shul , F. Ren, GaN: Processing, defects, and devices, J. Appl. Phys. 1(1999) 1-78. https://doi.org/10.1063/1.371145

[4] S. Gradečak, F. Qian, And. Li, H.G. Park, C.M. Lieber, GaN nanowire lasers with low lasing thresholds, Appl. Phys. Lett. 87(2005) 173111-1-3. https://doi.org/10.1063/1.2115087

[5] S. Pimputkar, J.S. Speck, S. Nakamura, Basic ammonothermal GaN growth in molybdenum capsules, J. Cryst. Growth 456(2016) 15 - 20. DOI:10.1016/j.jcrysgro.2016.07.034

[6] S. Sintonen, P. Kivisaari, S. Pimputkar, S. Suihkonen, T. Schulz, J. S. Speck, S. Nakamura, Incorporation and effects of impurities in different growth zones within basic ammonothermal GaN, J. Cryst. Growth456(2016)43-50.

https://doi.org/10.1016/j.jcrysgro.2016.08.040

[7] H. Okumura. S. Misawa, S. Yoshida, Epitaxial growth of cubic and hexagonal $\mathrm{GaN}$ on GaAs by gas-source molecular-beam epitaxy, Appl. Phys. Lett. 9(1991) 1058 - 1060. https://doi.org/10.1063/1.106344

[8] H. Vilchis, V.M, Sanchez, R.A. Escobosa. Cubic GaN layers grown by metalorganic chemical steam deposition on GaN templates obtained by ninitridation of GaAs, Thin Solid Films 520(2012) 5191 5194. https://doi.org/10.1016/j.tsf.2012.03.123

[9] H. Okumura, K.Ohta, G. Feuillet, K. Balakrishnan, S. Chichibu, H. Hamaguchi, Growth and characterization of cubic GaN, J. Cryst. Growth17(1997)113-133. https://doi.org/10.1016/S00220248(97)00084-5

[10] H. Li, R.J. Xie, N. Hirosaki, B. Dierre, T. Sekiguchi, Y. Yajima, Preparation and cathodoluminescense of $\mathrm{Mg}$-doped and $\mathrm{Zn}$-doped GaN powders, J. Am. Ceram. Soc. 91(5)(2008) 1711 - 1714. https://doi.org/10.1111/j.1551-2916.2008.02338.x

[11] J.K. Hite, T.J. Anderson, L.E. Luna, J.C. Gallagher, M.A. Mastro, J.A. Freitas, C.R. Eddy Jr, Influence of HVPE substrates on homoepitaxy of GaN grown by MOCVD, J. Cryst. Growth 498(2018) 352 - 356. https://doi.org/10.1016/j.jcrysgro.2018.06.032
[12] Z. Liliental-Weber, R. dos Reis, T. Sochacki, M. Bockowski, The influence of the substrate misorientation on the structural quality of GaN layers grown by HVPE, J. Cryst. Growth 498(2018) $346-351$. https://doi.org/10.1016/j.jcrysgro.2018.07.010

[13] C.P. Thao, D.H. Kuo, D.J. Jan, Codoping effects of the Zn acceptor on the structural characteristics and electrical properties of the Ge donor-doped $\mathrm{GaN}$ thin films and its heterojuntion diodes all made by reactive sputtering, J. Mat. Sci. Sem. Proc. 82(2018) 126-134. https://doi.org/10.1016/j.mssp.2018.04.002

[14] W.S. Jung, Synthesis and characterization of gallium nitride powders from a gallium(III) sulfate salt in flowing ammonia, J. Kor. Chem. Soc. 11(2003) 1058 - 1061. DOI: 10.4191/KCERS.2003.40.11.1058

[15] R. Garcia, G.A. Hirata, A.C. Thomas, F.A. Ponce, Structure and luminescence of nanocrystalline gallium nitride synthesized by a novel polymer pyrolysis route, Opt. Mater. 29(2006) $19-23$. https://doi.org/10.1016/j.optmat.2006.03.004

[16] T. Maruyama, H. Miyake, Gallium nitride thin films deposited by radio-frequency magnetron sputtering, J. Vac. Sci. Technol. A 4(2006) 1096 - 1099. https://doi.org/10.1116/1.2208988

[17] E. Gastellóu, C. Morales, R. García, G. García, G.A. Hirata, R. Galeazzi, A.M. Herrera, E. Rosendo, T. Díaz, J.R. Ramos, R. Romano, A. Coyopol, Enhanced crystalline size of undoped $\mathrm{GaN}$ powders obtained by nitridation of metallic gallium, Opt. Mater. 83(2018) 220-224. https://doi.org/10.1016/j.optmat.2018.06.021

[18] J.I. Langford, A.J.C. Wilson, Sherrer after Sixty Years: A survey and some new results in the determination of crystallite size, J. Appli. Cryst. 11(1978)102-113. https://doi.org/10.1107/S0021889878012844

[19] M.A. Reshchikov, H. Morkoç, Luminescence properties of defects in GaN, J. Appl. Phys. 97(2005) 061301-1 - 061301-95. https://doi.org/10.1063/1.1868059

[20] M.S. Kumar, J. Kumar, XRD, XPS, SEM, PL and Raman scattering analysis of synthesized GaN powder, Mat. Chem. Phys, 77(2002) 341-345. https://doi.org/10.1016/S0254-0584(02)00012-3

[21] G.N. Chaudhari, V.R. Chinchamalatpure, S.A. Ghosh, Structural and electrical characterization of GaN thin films on $\mathrm{Si}(100)$, Am. J. Analyt. Chem. 2(2011) 984-988. doi:10.4236/ajac.2011.28115 